\title{
Rational Emotional Behavior: How to reduce irrational beliefs in victims post-natural disasters
}

\section{Mawardi Djamaluddin, Suryani Hi. Umar}

\author{
IAIN Ternate, Indonesia \\ mawardidjamaluddin@iain-ternate.ac.id
}

Submitted : 19-04-2021, Revised : 02-05-2021, Accepted : 27-05-2021

\begin{abstract}
Natural disasters that occur over a long period of time and the level of damage that occurs often affect the psychological condition of the individual causing individuals to experience traumatic experiences that are hard to forget. Traumatic experiences experienced as a result of natural disasters also influence one's view of the natural disaster itself. Some people may have rational views while others have irrational views. This irrational view often makes individuals feel even more traumatized by the bad experiences they have experienced. Therefore, this study aims to examine the effectiveness of rational emotive behaviour counselling in reducing irrational beliefs experienced by people experiencing natural disasters. The research method used was quantitative with an experimental design. The research subjects were earthquake victims in Tomara Village, South Halmahera Regency who had irrational beliefs in the high category based on the results of filling in data from the irrational belief scale. The results showed that rational emotive behaviour therapy counselling was effective in reducing irrational beliefs experienced by people experiencing natural disasters.
\end{abstract}

Keywords: Irrational Beliefs; Post-Natural Disasters; Rational Emotive Behavior

\section{Introduction}

In 2019, the National Disaster Management Agency released a report indicating that 3,622 natural disasters occurred across the region during 2019 , it is estimated that $90 \%(2,699)$ were caused by hydrometeorological phenomena such as tornadoes, floods and landslides. The National Disaster Management Agency also noted that 3,397 natural disasters that occurred in 2018, around 2,500 were related to hydrological factors, although the largest number occurred in 2019, but the number of victims who died was 475 people and lost as many as 108 people, however, natural disasters that occurred during the last few years when the earthquake and tsunami occurred in several regions in Indonesia resulted in the death of 4,231 people (Asianews, 2019).

This data shows that Indonesia is one of the countries with a geographical condition which is quite prone to natural disasters. One of the natural disasters that cause a lot of casualties is an earthquake which tends to have a significant impact on both the dead and other physical buildings. North Maluku, as one of the provinces in Indonesia which has the characteristics of an archipelago and is located within the Pacific ring of fire, is always at risk from earthquakes, volcanic eruptions, floods and tsunamis. Meanwhile, in the context of Indonesia's geographical conditions, an even bigger threat comes from an earthquake that threatens around 11 million people and floods that threaten at least 1 million people (BBCIndonesia, 2018). An earthquake with 7.2 magnitude on the Richter scale has occurred in Gane Barat, South Halmahera Regency some time ago. The impact of the earthquake was very much felt in Tomara Village, Bacan District, Middle East District, South Halmahera Regency, based on the results of interviews to photograph the condition of the community after the earthquake and the psychological problems faced, showed that the condition of the people of South Halmahera, especially in Tomara Village, experienced significant trauma conditions because This is the first time feeling an earthquake with a large enough duration and vibration, so that several houses were damaged but did not have an impact until they died. Even so, what made the community feel more traumatized was the information that a tsunami would occur, which was spread through short messages, causing people to flee to high places. The community also felt the trauma after the earthquake which lasted for several weeks before gradually recovering. 
Beside that, the problem faced by the community is that the availability of assistance for the renovation of damaged residential buildings has not been fully accepted by the whole community. With regard to psychological treatment, in particular, regular staining has not been given to monitor the psychological recovery process in the community and also the psychological treatment methods given to children as well as adolescents and adults because the trauma recovery process is mostly given to children while adolescents and adults are not given because they think that adolescents and adults do not experience a significant impact. The length of time living in a refugee camp also affects the psychological condition of the community, even though there is no aftershock with a large enough shock, living in a refugee camp for several days is the first experience for some people that affects their comfort in their daily life. Therefore, some people prefer to return to their homes even though they still feel fear if an earthquake occurs again. The psychological condition of people who also experience an impact on their physical health conditions, especially those with congenital diseases which are often exacerbated by the difficulty sleeping disorder that is felt at night as a result of the feeling of trauma caused by the earthquake.

Psychologically, the effect of natural disasters can be measured from four dominant parameters, namely the scope of the disaster, the severity or damage of the disaster, and the speed or duration of the disaster, and the type of disaster that occurs (King \& Vogt, 2015). In general, someone who experiences it natural disasters with a high level of severity or damage, long duration, and types of disasters that are very traumatic (for example earthquakes), of course, have a more significant psychological impact than those with a less severe degree of occurrence (Khan, K., Gulzar, S., \& Yahya, 2013). However, parameters related to the environmental scope of a disaster do not always correlate with the level of traumatic experience experienced by a person, for example, a misfortune or disaster experienced by a person within the scope of his family may have a more psychological impact when compared to natural disasters experienced by the community in general. This shows that the level of psychological resilience of a person to natural disasters is greatly influenced by how the perception given to the disaster is experienced. Individuals often experience exccesive stress reactions, find it difficult to restart their daily activities, and experience prolonged grief (Bland, 2018). Individuals who experience natural disasters can go through a physical recovery process, but often experience difficulty in going through the stages of recovery psychologically because they experience traumatic conditions for a long duration (Hyland, P., \& Boduszek, 2012). The physically injured individual will also experience a psychological burden "a distress state associated with physical injury" and an increased risk of developing posttraumatic stress disorder (PTSD) (Zatzick, 2017). Symptoms related to the PTSD condition were also experienced by several communities who were victims of the earthquake in South Halmahera who stated that the damage to buildings and some of their injured family members made the psychological pressure he felt heavier, this was exacerbated by the absence of assistance in the form of the necessary foodstuffs and media measures. Therefore, it is necessary to handle systematically and integratively to reduce various potential psychological problems that may occur in the future, this happens because each individual has a tendency to repeat his traumatic experiences in his long-term memory.

\section{Methods}

This research is a quantitative study using an experimental design. In particular, the experimental design used is a true experimental design (Creswell, 2012). The main focus of this research is how to test the implementation of REB counselling services to the level of reduction in irrational beliefs among victims of natural disasters. The population in this study are people who live in South Halmahera, North Maluku Province who are affected by natural 
disasters and the research sample is individuals who have high irrational beliefs based on the results of the irrational belief scale score in communities who are victims of natural disasters. The data collection technique used was a psychological scale of irrational beliefs. The instrument used was an irrational confidence scale that had item validity that met valid criteria or $\geq 0.3$ on all items totalling 36 items with a score range of $0.30-0.73$. This study used two statistical analyzes, namely the Wilcoxon signed-rank test analysis and the Mann-Whitney U test analysis.

\section{Results and Discussion}

Determination of the research subject was carried out in two main stages, namely filling in the irrational belief scale against the disaster and in-depth interviews to measure the level of irrational beliefs possessed by the research subject. Research subjects who have a high irrational belief score then follow the second stage, namely in-depth interviews to confirm the data obtained from the results of filling in the irrational belief scale against the disaster. After going through these stages, ten research subjects were determined with the results of the scores on the irrational beliefs scale and the results of in-depth interviews who were designated as research subjects in the experimental group. In addition, a scale of irrational belief in the disaster was also given to research subjects who had participated in psychosocial activities in the form of trauma healing carried out by related institutions/agencies which were then designated as the control group, so that 10 research subjects were obtained for the control group. Research subjects in the experimental group and the control group are described in table 1 below:

Table1.scores of irrational beliefs of candidate research subjects in the experimental group control group

\begin{tabular}{llll|llll}
\hline & Experimental Group & & \multicolumn{4}{c}{ Control Group } \\
\hline Subjects & Age & Score & Category & Subjects & Age & Score & Category \\
\hline AKK & 19 & 141 & High & RAL & 19 & 138 & High \\
\hline RVK & 23 & 145 & High & WH & 23 & 137 & High \\
\hline YA & 26 & 138 & High & MRS & 20 & 143 & High \\
\hline SL & 31 & 130 & High & IJ & 37 & 152 & High \\
\hline RAL & 22 & 140 & High & MM & 33 & 130 & High \\
\hline HS & 24 & 120 & High & RB & 25 & 128 & High \\
\hline JUS & 18 & 150 & High & WOH & 19 & 135 & High \\
\hline MLP & 35 & 133 & High & DPR & 17 & 138 & High \\
\hline RJ & 40 & 144 & High & LA & 26 & 134 & High \\
\hline ALE & 29 & 123 & High & AJK & 22 & 147 & High \\
\hline
\end{tabular}

There was no significant difference in scores when the pretest was a prerequisite for the possibility of a study using the pretest-post-test control group design. Based on the statistical test output, it is known that the $\mathrm{Z}$ test value is -0.114 and the Asymp value. Sig. (2-tailed) of 0.912. Hence, the Asymp. Sig. (2-tailed) $\geq$ significant level $\alpha / 2=0.05$ (0.910>0.05), so it can be concluded that there is no significant difference in values between the experimental group and the control group on the pretest score, so the intervention process can be carried out, such as described in table 2 below: 
Tabel 2 Significance of the Pretest Score

\begin{tabular}{ll}
\hline & Hasil Post Test \\
\hline Mann-Whitney & 24.000 \\
\hline Wilcoxon W & 79.000 \\
\hline Z & -1.967 \\
\hline Asymp. Sig. (2-tailed) & .049 \\
\hline Exact Sig. (2*(1-tailed Sig.) & 0,52 \\
\hline
\end{tabular}

Implementation of Experimental Group Interventions. The intervention was given by the researcher himself as the trainer. During the research process, a pretest was given using an irrational belief scale to identify the high irrational beliefs of earthquake victims. Furthermore, given the intervention to apply REB counselling. In the final stage, the posttest is given to research subjects who receive counselling services after participating in the entire counselling process. Based on the data obtained, the decline in the score on the research subjects can be grouped into two, namely the group that experienced a change from high to medium and high to low categories. There are three subjects that fall into the category of high to moderate change, namely RAL, JUS, and RJ. Meanwhile, there were seven subjects included in the high to low change category, namely AKK, RVK, YES, SL, HS, MLP and ALE.

While the intervention process was not carried out specifically for the control group for research purposes but refers to the approach or program that has been designed by the relevant agencies in providing psychosocial services in overcoming post-disaster trauma (Post Traumatic Stress Disorder). The research process begins by identifying the initial conditions for irrational beliefs about calamities that the research subjects have in the control group through the pretest using the same irrational belief scale against disasters as the instrument given to the experimental group, then given the posttest. Based on the data obtained, the decrease in the scores of research subjects in the control group can be grouped into two, namely the group that experienced a change from the high category to the medium category and the group that did not change (still in the high category). The data for decreasing irrational confidence scores in the experimental group and the control group are described in table 3 below:

Table 3. The results of the pre-test and post-test in the experimental group and control group

\begin{tabular}{llllll|llllll}
\hline \multicolumn{4}{c|}{ Experimental Groups } & \multicolumn{5}{c}{ Control Groups } \\
\hline Sub & $\begin{array}{l}\text { Pre } \\
\text { test }\end{array}$ & Category & $\begin{array}{c}\text { Post } \\
\text { test }\end{array}$ & Category & $\begin{array}{c}\text { Decrease } \\
\text { in score }\end{array}$ & Sub & $\begin{array}{c}\text { Pre } \\
\text { test }\end{array}$ & Category & $\begin{array}{c}\text { Post } \\
\text { test }\end{array}$ & $\begin{array}{c}\text { Category } \\
\text { Decrea } \\
\text { se in } \\
\text { score }\end{array}$ \\
\hline AKK & 141 & High & 54 & Low & 87 & RAL & 138 & High & 113 & Medium & 25 \\
\hline RVK & 145 & High & 71 & Low & 74 & WH & 137 & High & 97 & Medium & 40 \\
\hline YA & 138 & High & 55 & Low & 83 & MRS & 143 & High & 88 & Medium & 55 \\
\hline SL & 130 & High & 58 & Low & 72 & IJ & 152 & High & 140 & High & 12 \\
\hline RAL & 140 & High & 118 & Medium & 22 & MM & 130 & High & 118 & Medium & 12 \\
\hline HS & 120 & High & 67 & Low & 53 & RB & 128 & High & 102 & Medium & 26 \\
\hline JUS & 150 & High & 125 & Medium & 25 & WOH & 135 & High & 94 & Medium & 41 \\
\hline MLP & 133 & High & 59 & Low & 74 & DPR & 138 & High & 96 & Medium & 42 \\
\hline RJ & 144 & High & 120 & Medium & 24 & LA & 134 & High & 125 & High & 9 \\
\hline ALE & 123 & High & 66 & Low & 57 & AJK & 147 & High & 115 & Medium & 32 \\
\hline
\end{tabular}

To measure the hypothesis in this study using the Wilcoxon signed-rank test and the Mann Whitney U Test. The results of the Wilcoxon signed-rank test were used to determine the differences before treatment and after being given intervention. The results of the Wilcoxon analysis of the experimental group in this study were: 
Tabel 4. Analysis of Wilcoxon signed rank test

\begin{tabular}{lllll}
\hline & & N & Mean Rank & Sum of Ranks \\
\hline Post Test - Pre Test & Negative Ranks & 10 & 5.50 & 55.00 \\
\hline & Positive Ranks & 0 & 00 & 00 \\
\hline Ties & 0 & & \\
\hline Total & 10 & & \\
\hline
\end{tabular}

Based on the results of the Wilcoxon test in the experimental group, there was a significant decrease in the irrational confidence score after receiving the intervention (posttest) in the experimental group compared to the value before the intervention (pretest), this can be seen from the Sig value. (2-tailed) of $0.005 \leq$ significant level ( $\alpha / 2=0.05$ ). The details can be seen in the following table:

Table 5. Statistics test

\begin{tabular}{ll}
\hline & Post Test - Pre Test \\
\hline $\mathbf{Z}$ & -2.803 \\
\hline Asymp. Sig. (2-tailed) & .005 \\
\hline
\end{tabular}

There were differences that occurred in the control group. The Wilcoxon test results in the control group can be seen in the following table:

Table 6. Analysis of Wilcoxon signed rank test

\begin{tabular}{lllll}
\hline & & N & Mean Rank & Sum of Ranks \\
\hline Post Test - Pre Test & Negative Ranks & 10 & 5.50 & 55.00 \\
\hline & Positive Ranks & 0 & 00 & 00 \\
\hline Ties & 0 & & \\
\hline Total & 10 & & \\
\hline
\end{tabular}

Based on this table, in the control group there was a significant decrease in the irrational confidence score after receiving the intervention (posttest) in the control group compared to the value before the intervention (pretest). This can be seen from the results of the Asymp value. Sig. (2-tailed) of $0.005 \leq$ significant level $(\alpha / 2=0.05)$. The details can be seen in the following table:

Table 7. Statistics test

\begin{tabular}{cc}
\hline & Post Test - Pre Test \\
\hline $\mathbf{Z}$ & -2.805 \\
\hline Asymp. Sig. (2-tailed) & .005 \\
\hline
\end{tabular}

The second hypothesis test, namely the Mann-Whitney U Test analysis test, was conducted to measure the effectiveness of rational emotive behaviour by calculating the difference in value after being given treatment (posttest) between the control group and the experimental group. The results are as follows:

Table 8 the Mann Whitney U Tets analysis

\begin{tabular}{ll}
\hline & Hasil Post Test \\
\hline Mann-Whitney & 24.000 \\
\hline Wilcoxon W & 79.000 \\
\hline $\mathbf{Z}$ & -1.967 \\
\hline Asymp. Sig. (2-tailed) & .049 \\
\hline Exact Sig. (2*(1-tailed Sig.) & 0,52 \\
\hline
\end{tabular}


Empirically, the decrease in the mean score of the experimental group was higher than the control group based on the average score in the experimental group before being given treatment (pretest) of 136.4 and after being given treatment (posttest) there was a decrease in the average score to 79.3. That is, in the control group the average value obtained before being given treatment (pretest) was 138.2 and after being given treatment (posttest) decreased to 108.8. Therefore, it can be concluded that the mean value of the experimental group has a greater decrease than the mean value of the control group by referring to the average posttest score obtained. This also shows that counseling services with the REB approach are effective in reducing the irrational beliefs of research subjects about the disaster experienced. The research results obtained have theoretical and empirical relevance based on arguments put forward by several experts, for example (Eseadi., Oyeoku., Onuigbo., 2019) who emphasized that REB counseling can be used to alter beliefs related to trauma (trauma-specific) beliefs. Besides that, (Hyland, P., \& Boduszek, 2012) say that events that trigger trauma are usually associated with raising irrational beliefs, such as demandingness beliefs, catastrophizing beliefs, low frustration tolerance beliefs, and depreciation beliefs in the cognitive building of each individual, thereore REB counseling has relevance in reducing irrational beliefs held by everyone. This is reinforced by views of (Prabandari, D., Sukarja, M., \& Maryati, 2018) concluded that cognitive behavior counseling which later became known as REB counseling had a significant effect on reducing the level of PTSD symptoms (symptoms), (Shubina, 2015) formulated an integrative approach between cognitive behavior counseling as the main approach in reducing PTSD symptoms, which was later called PTSD cognitive-behavioral therapy. However, the model offered still requires a lot of in-depth research to obtain scientific and empirical proof. This shows that REB counseling is a counseling approach that has practical and conceptual relevance in overcoming various kinds of PTSD symptoms.

This study shows that REB counselling is effective in reducing irrational beliefs after an accident. Ellis as the pioneer of REB counselling has formulated parameters that show that each individual has the potential to have irrational beliefs about the experiences they experience if the experience leads to forms of failure, rejection, and poor treatment accepted by individuals (Dryden, 2017). Therefore, as the antithesis of this rule, it can be concluded that if individuals get experiences that lead to success, acceptance, and good treatment, then this experience will stimulate rational beliefs compared to irrational beliefs. The same thing is shown by every individual who has had a bad experience, but when the bad experience is followed by adequate support from the social environment, the rational beliefs possessed by these individuals tend to dominate more than irrational beliefs.

Furthermore, it is said that the rational beliefs and irrational beliefs possessed by a person are like opposite poles, the poles of rational belief are defined by cognitive abilities or thoughts that lead to beliefs that are flexible and not extreme in responding to something that happens to him or her manifested in forms of anger and sadness that are healthy or can be controlled, on the contrary, irrational beliefs are identical to beliefs that tend to be rigid and extreme in responding to the difficulties faced by them, leading to dysfunctional emotions such as anxiety, feelings of anger, and depression unhealthy or uncontrolled (Dryden, 2019). REB counseling services also lead to a very strong preference deconstruction process by each individual or community in viewing natural disasters as a bad experience that has the potential to destroy the social and economic order of life. In this regard, the tendency for humans to adopt irrational beliefs is based on the idea that it is difficult to think rationally in the face of important situations where preferences are very strong (Dryden, W., \& Branch, 2018)

The results of the study, based on Wilcoxon analysis, showed that in the experimental group there was a decrease in irrational beliefs before and after being given REB counseling services. REB counseling has a fundamental goal of replacing irrational beliefs with rational beliefs to reduce dysfunctional emotions such as anxiety, anger, and unhealthy depression. The 
REBT therapeutic process first encourages the client or group to understand that in the face of failure, rejection, and poor care, it is their irrational beliefs (B) that cause dysfunctional emotional and behavioral responses (C), not events (A) themselves. Once this ABC framework is understood, clients are encouraged to refute (D) their irrational beliefs and replace them with rational alternatives (E). The main purpose of disagreement in REBT is to help clients understand that their irrational beliefs are wrong, illogical, and unhelpful, and that rational alternatives are right, logical, and helpful (Dryden, 2019). This shows that the REB counseling service aims to make irrational beliefs from the community towards the disaster being faced into a more rational belief. The results obtained also show the same parameters, namely the decline in irrational beliefs of research subjects after receiving REB counseling services. In line with this theory, REB counseling can also be considered as a motivation theory (David, 2017) which not only leads to a restructuring process of the research subject's thought processes that were previously irrational to be more rational but can also act as stimulation which is expected to motivate research subjects to think in a more rational way. rational in dealing with difficulties in everyday life. Several studies show that the formation of a person's irrational beliefs is strongly influenced by his assessment of the difficult situation at hand (appraisal of a situation) so that it gives a certain emotional response according to the assessment given (Hyland, P., \& Boduszek, 2012). Basically, it is irrational beliefs that cause anxiety in a person, not only difficult situations that trigger this anxiety (Harris, S., Davies, M. F., \& Dryden, 2016).

\section{Conclusions and Suggestions}

Based on the results of research conducted regarding the effectiveness of REB counseling to reduce the irrational beliefs of people affected by the earthquake in South Halahera district, it can be concluded that REB counseling reduces the irrational beliefs of people affected by natural disasters. The effectiveness of REB counseling is indicated by the decreasing score of the irrational confidence scale after being given treatment (posttest) in the experimental group which is statistically significantly greater than the control group.

The research subjects showed irrational beliefs about the disasters they experienced in order to be more adaptive in terms of the emergence of disasters that occurred, feelings that emerged about the disasters they experienced, as well as behaviours shown towards disaster experiences. A more adaptive trust is achieved with the REB counselling service which consists of the following stages: cognitive methods, emotional methods, and behavioural techniques. The results of this study are expected to be a model of a counselling approach that can be applied by the Islamic education counselling study program IAIN Ternate as part of the development of a study program in providing community service in the context of preventive and curative efforts for various psychological problems experienced. by the general public, especially with regard to traumatic experiences.

\section{References}

Asianews. (2019). Indonesia experienced 3,622 natural disasters in 2019. Retrieved August 13, 2020, from http://www.asianews.it/news-en/Indonesia-experienced-3,622-naturaldisasters-in-2019-48854.html

BBC-Indonesia. (2018). Potensi Bencana Alam di Indonesia.

Bland, M. (2018). Some problems with sample size. The Joint Meeting of the Dutch Pathological Society and the Pathological Society of Great Britain \& Ireland. Leeds.

Creswell, J. w. (2012). Educational Reserach: Palnning, Conducting, And Evaluating Quantitaive dan Qualitative Research. (Fourth). Pearson. 
David, D. (2017). Rational emotive behavior therapy (REBT): The view of a cognitive psychologist. New York: Brunner-Routledge.

Dryden, W., \& Branch, R. (2018). The fundamentals of rational-emotive behavior therapy. West Sussex: Wiley.

Dryden, W. (2017). The practice of rational-emotive behavior therapy. New York: Springer Publishing Company.

Dryden, W. (2019). How to think and intervene like an REBT therapist. London: Routledge.

Eseadi., Oyeoku., Onuigbo., \& O. (2019). Rational-Emotive Behavior Therapy Program for Trauma-Specific Beliefs Among Undergraduate Students: Testing the Effect of A Group Therapy. Global Journal of Health Science, 11(8).

Harris, S., Davies, M. F., \& Dryden, W. (2016). An experimental test of a core REBT hypothesis: Evidence that irrational beliefs lead to physiological as well as psychological arousal. Journal of Rational-Emotive and Cognitive-Behavior Therapy, 24, 1-9. https://doi.org/10.1007/s10942-005-0019-5

Hyland, P., \& Boduszek, D. (2012). A unitary or binary model of emotions: A discussion on a fundamental difference between cognitive therapy and rational emotive behaviour therapy. Journal of Humanistics and Social Sciences, 1(1), 49-61.

Khan, K., Gulzar, S., \& Yahya, S. (2013). Crucial factors affecting stress: A study among undergraduates in Pakistan. International Journal of Asian Social Science, 3(2), 428-442.

King \& Vogt. (2015). Risk and resillience factors in the etiology of chronic of PTSD. The Guilford Press.

Prabandari, D., Sukarja, M., \& Maryati, G. (2018). Pengaruh Cognitive Behavioral Therapy (CBT) terhadap Post Traumatic Stress Disorder (PTSD) Pada Pasien Post Kecelakaan Lalu Lintas di RSUP Sanglah Denpasar. Coping : Community of Publishing in Nursing, $3(2), 22-26$.

Shubina, I. (2015). Cognitive-behavioral therapy of patients with ptsd: literature review. Procedia - Social and Behavioral Sciences, 208-2016.

Zatzick, M. (2017). Interventions for acutely injured survivors of individual and mass trauma. In Textbook of Disaster Psychiatry (Dalam Ursa, pp. 190-205). United Kingdom: Cambridge University Press. 